EXPERIENCE WITH RITUXIMAB BIOSIMILAR BCD020 IN PATIENTS WITH RHEUMATOID ARTHRITIS IN REAL-WORLD CLINICAL PRACTICE ACCORDING TO DATA FROM MOSCOW UNIFIED ARTHRITIS REGISTRY (MUAR)

G. Lukina $^{1,2}$, E. Koltsova ${ }^{1,3}$, E. Shmidt ${ }^{4}$, K. Lytkina ${ }^{5}$, E. Zhilyaev ${ }^{6,7},{ }^{1}$ A.S. Loginov Moscow Clinical Scientific Center, Moscow, Russian Federation; ${ }^{2} V . A$. Nasonova Research Institute of Rheumatology, Moscow, Russian Federation; ${ }^{3}$ Research Institute of the Organization of Health and Healthcare Management, Moscow, Russian Federation; ${ }^{4}$ N.I. Pirogov City Clinical Hospital ${ }^{1}$, Moscow, Russian Federation; ${ }^{5}$ City Clinical Hospital ${ }^{4}$, Moscow, Russian Federation; ${ }^{6}$ European Medical Center, Moscow, Russian Federation; ${ }^{7}$ Russian Medical Academy of Continuous Professional Education of the Ministry of Healthcare of the Russian Federation, Moscow, Russian Federation

Background: The introduction of perspective anti-rheumatic biologic agents into clinical practice has not only increased therapy efficacy and improved medical prognosis in patients with rheumatoid arthritis (RA), but also resulted in a dramatic increase in treatment cost and, therefore, in a reduced accessibility of the innovative treatment for patients. For this reason, over the last years, there has been a huge interest towards developing biosimilars $[1,2]$.

Objectives: To assess the effectiveness and safety of switching from reference rituximab $\left(R T X_{\text {ref }}\right)$ to rituximab biosimilar $\left(R T X_{b s}\right) B C D-020$ in patients with $R A$ in real clinical practice according to the data from MUAR.

Methods: Patients with RA who treated by RTX $\mathrm{ref}_{\text {at }}$ at the onset and then switched to RTX (BCD-020) were enrolled in the study. For all patients were performed: swollen and tender joints count, ESR, CRP, biochemistry and immunologic blood analyses. Assessment of dynamic of DAS28, RAPID3, HAQ-DI was performed. The great attention was given to the therapy safety

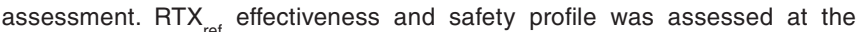
moment of switching; data for RTX ${ }_{b s}$ (BCD-020) were collected not earlier than 6 months after switching.

Results: 46 patients with RA were enrolled, $80.5 \%$ were women; the mean age was $59.5 \pm 12.2$ years; $91.3 \%$ were RF-positive, $63 \%$ - ACCPA-positive, the disease activity at the moment of switching was moderate, the mean DAS28 was 3.5. The duration of RTX therapy until switching was $36.8 \pm 26.8$ months; the duration of the follow-up period for BCD-020 biosimilar was $12.1 \pm 6.18$ months. In $43.5 \%$ of patients, previously inefficiency or intolerance of other biologics was discovered. The proportion of patients who received concomitant therapy with glucocorticoids or methotrexate (MTX) was $45.7 \%$ and $43.5 \%$, respectively. The mean MTX dose was $13.6 \mathrm{mg} / \mathrm{wk}$. The mean dose of RTX $\mathrm{ref} / \mathrm{BCD}-020$ was $1000 \mathrm{mg}$. The stability dynamic of clinical parameters was retained after switching to biosimilar (Tab.1) without significant difference between the rituximab products $(\mathrm{p}>0.05)$

Table 1. Comparison of Efficiency Parameters for the Reference Rituximab and Biosimilar BCD-020

\begin{tabular}{lcc}
\hline Parameter & $\begin{array}{c}\text { Reference } \\
\text { rituximab }\end{array}$ & $\begin{array}{c}\text { Biosimilar } \\
\text { BCD-020 }\end{array}$ \\
\hline DAS28 (ESR) & 3.39 & 3.34 \\
HAQ-DI & 1.48 & 1.44 \\
RAPID3 & 12.9 & 12.6 \\
\hline
\end{tabular}

The safety profile of $\mathrm{RTX}_{\text {ref }}$ and $\mathrm{RTX}$ bs (BCD-020) was also similar. None of the patients discontinued $\mathrm{BCD}-020$ therapy for reasons related to safety or inefficiency.

Conclusion: Within the framework of routine clinical practice, switching from reference rituximab to $\mathrm{BCD}-020$ biosimilar is not accompanied by a change in efficiency and safety profile of the therapy and does not pose a risk of discontinuation, which is coherent with the results of the registration clinical trial for BCD-020. [3]

References:

[1] Edwards CJ, et al. Switching to biosimilars: current perspectives in immune-mediated inflammatory diseases. Expert Opin Biol Ther. 2019 Oct;19(10):1001-1014. doi: 10.1080/14712598.2019.1610381. Epub 2019 May 6.

[2] Dörner T, et al. The changing landscape of biosimilars in rheumatology. Ann Rheum Dis 2016;75:974-982. doi:10.1136/annrheumdis2016-209166

[3] Nasonov EL, et al. The results of a phase III comparative clinical trial of rituximab (Acellbia and MabThera) in rheumatoid arthritis (the BIORA study). Nauchno-Prakticheskaya Revmatologiya $=$ Rheumatology Science and Practice. 2016;54(5):510-519 (In Russ.). doi: http://dx.doi. org/10.14412/1995-4484-2016-510-519
Disclosure of Interests: Galina Lukina Speakers bureau: Novartis, Pfizer, UCB, Abbvie, Biocad, MSD, Roche, Ekaterina Koltsova: None declared, Evgeniya Shmidt Speakers bureau: MSD, Novartis, Pfizer, Karine Lytkina Speakers bureau: Novartis, Eli Lilly, Pfizer, UCB, Abbvie, Biocad, MSD, Jonson\&Jonson, Evgeniy Zhilyaev Speakers bureau: Novartis, UCB, Pfizer, Biocad, Abbvie, MSD, Roche DOI: 10.1136/annrheumdis-2020-eular.4093

\begin{tabular}{|l|l}
\hline AB0307 & DOES FCGR2A, FCGR3A AND FCGR3B \\
POLYMORPHISM CAN PREDICT ANTI-DRUG \\
ANTIBODIES APPARITION IN RHEUMATOID \\
ARTHRITIS PATIENTS TREATED WITH \\
TNF-BLOCKERS?
\end{tabular}

I. Mahmoud ${ }^{1}$, M. Moalla ${ }^{1}$, A. Ben Tekaya ${ }^{1}$, S. Bouden ${ }^{1}$, R. Tekaya ${ }^{1}$, O. Saidane ${ }^{1}$ I. Sfar ${ }^{2}$, Y. Gorgi ${ }^{2}$, L. Abdelmoula ${ }^{1} .{ }^{1}$ Hospital Charles Nicolle, Rheumatology, Tunis, Tunisia; ${ }^{2}$ Charles Nicolle Hospital, Immunology, TUNIS, Tunisia

Background: Fc gamma receptors (FcyRs) play a major role in the regulation of humoral immune responses. Single-nucleotide polymorphisms (SNPs) of FCGR2A and FCGR3A and FCGR3B can impact the expression level, IgG affinity and function of the CD32 and CD16 FcyRs in response to their engagement by the Fc fragment of IgG. It was described in patient treated for rheumatoid arthritis (RA), that such a polymorphism may influence patients response to TNF-blockers.

Objectives: In this study, we aimed to investigate whether the FCGR2A H131R (rs1801274), FCGR3A F158V (rs396991), and FCGR3B NA1/NA2 polymorphisms can be involved in the genesis of anti-drug-antibody ADAb to anti-TNF therapy in RA patients under etanercept (ETA), adalimumab (ADL) and infliximab (INF).

Methods: We included 47 patients treated for RA under TNF-blockers. To assess the association between the FCGR2A H131R (rs1801274), FCGR3A F158V (rs396991), and FCGR3B NA1/NA2 polymorphisms and immunogenicity of TNF-blockers, we used allele contrast, the recessive model, the dominan model, and the homozygote contrast. Quantitative measurements of the ADAbs was carried out by a commercial enzyme-linked immunosorbent assay (ELISA) kit (Promonitor) $)^{\circledR}$ after 6 months of treatment.

Results: We involved 18 patients treated with ETA, 13 patients with ADL and 16 under INF. None of the patients under ETA has developed ADAb and respectively 1 and 7 patients developed immunogenicity with ADL and INF. We excluded patients under ETA from statistical study since they didn't develop ADAb.

A significant association was revealed between FCGR2A H131R polymorphism and immunogenicity of INF and ADL (table 1).

Table 1. Association between FCGR2A polymorphism and immunogenicity to INF and ADL

FCGR2A association with ADAb

( $\mathrm{n}=29$, crude analysis)

\begin{tabular}{lcccc}
\hline Genotype & ADAb=0 & ADAb=1 & OR (95\% Cl) & P-value \\
\hline H/H & $1(4.8 \%)$ & $3(37.5 \%)$ & 1.00 & 0.031 \\
H/R-R/R & $20(95.2 \%)$ & $5(62.5 \%)$ & $\mathbf{0 . 0 8 ( 0 . 0 1 - 0 . 9 8 )}$ &
\end{tabular}

There weren't significant associations between ADAb's development and FCGR3A F158V and FCGR3B NA1/NA2 polymorphism.

Conclusion: FCGR2A R allele carriers show less susceptibility to develop $A D A b$ to $A D L$ and INF with follow-up times of 6 months. Our results provide an explanation for controversies in the relationships between FCGR2A H131R polymorphism and TNF-blockers response. Further studies with larger population of RA patients should be undertaken to confirm this hypothesis.

References: None

Disclosure of Interests: None declared

DOI: 10.1136/annrheumdis-2020-eular.4540

\section{AB0308 NO SIGNS OF CONGESTIVE HEART DISEASE PROGRESSION IN PATIENTS WITH RHEUMATOID ARTHRITIS ON IL-6 RECEPTOR ANTAGONIST AFTER 12 MONTHS TREATMENT}

A. Martynova ${ }^{1}$, T. Popkova ${ }^{1}$, H. Gerasimova ${ }^{1} .{ }^{1}$ V.A. Nasonova Research Institute of Rheumatology, Systemic Rheumatic Disorders, Moscow, Russian Federation

Background: N-terminal pro-brain natriuretic peptide (NT-proBNP) is a known marker of heart dysfunction, mainly described in patients with high activity of rheumatoid arthritis (RA). Further knowledge of the influence of the IL-6 receptor 